\title{
Evaluation of Kinetic Approach in Describing Potassium Bioavailability
}

\author{
Monier Morad Wahba*, Amal M. Aziz, Alaa M. Zaghloul \\ Soils and Water Use Department, Agricultural Division, National Research Centre, Cairo, Egypt
}

Email address:

moniermorad@yahoo.com (M. M. Wahba)

${ }^{*}$ Corresponding author

To cite this article:

Monier Morad Wahba, Amal M. Aziz, Alaa M. Zaghloul. Evaluation of Kinetic Approach in Describing Potassium Bioavailability. American Journal of Heterocyclic Chemistry. Vol. 3, No. 6, 2017, pp. 78-85. doi: 10.11648/j.ajhc.20170306.14

Received: November 11, 2017; Accepted: November 27, 2017; Published: December 26, 2017

\begin{abstract}
The objective of this study was to determine the potassium (K) release kinetics of sandy soil sample representative soil of Egyptian new reclaimed areas as affected by treatments of different rates of compost and chemical fertilizers applied individually or mixture of both type sand the effect of two irrigation regimes i.e. 80 and $60 \%$ of water requirements IR. Four mathematical models (power function, Elovich, parabolic diffusion and first-order) were used to fitted the data describe $\mathrm{K}$ desorption reactions involving 168-hr cumulative reaction time. Comparison of the models using the coefficient of determination $\left(\mathrm{r}^{2}\right)$ and the standard error of the estimate (SE) indicated that the Elovich and the power function equations overall displayed the best fitted ones. The first-order rate and for less extent, parabolic diffusion equation were less fitted to describe the kinetic data. The constants of the best fitted models represent the rate of $\mathrm{K}$ release indicated that all treatments applied to soil gave high and significant increase in rate of $\mathrm{K}$ release compared to the control (untreated soil). According to the same constants values, the organic fertilizer applied was the lowest one, meanwhile the chemical one was the highest values, the mixture treatments values, however, were in between the chemical and organic treatments. In addition, the $80 \%$ of IR gave the best water management in having both high $\mathrm{K}$ adsorption from used soil and significant $\mathrm{K}$ uptake by corn plant.
\end{abstract}

Keywords: Kinetic Methods, Potassium Adsorption, Kinetic Models, Power Function Equation

\section{Introduction}

Potassium is an element essential for plant growth and its importance in agriculture is well recognized [1]. Although the distribution of $\mathrm{K}+$ forms differs from soil to soil as a function of the dominant soil minerals present, total soil $\mathrm{K}+$ reserves are generally large. Soil $\mathrm{K}+$ is typically divided into four forms: soil solution $\mathrm{K}+$, exchangeable $\mathrm{K}+$, nonexchangeable $\mathrm{K}+$, and $\mathrm{K}+$ in soil minerals.

Kinetics of chemical reactions in soil and aquatic environments is a topic that is of extreme importance. Most of chemical processes that occur in these systems are dynamic, and knowledge of the mechanisms and kinetics of these reactions is fundamental. Moreover, to properly understand the fate of applied fertilizers, pesticides, and organic pollutants in soils with time, and to thus improve nutrient availability and the quality of our groundwater, it must study kinetics.
An array of kinetic methods has been used to measure the rates of soil chemical process. Anion exchange resin (AER) for studying the kinetics of soil chemical process was established in 1955 by Amer et al. [2]. As an alternative method for characterizing soil P, the use of an (AER) would remove $\mathrm{P}$ from the soil solution; its action would be more nearly analogous to that of the plant P-uptake. The use of (AER) involves placing an adsorbent and the adsorptive in a vessel such as centrifuge tube. The suspension is agitated using reciprocating shaker for several time intervals. Then the suspension is usually centrifuged to separate a clear supernatant solution for subsequent analysis. The use of centrifugation to separate the liquid from solid phase in this method or any batch technique has several disadvantages. Centrifugation would create electro-kinetic effects close to soil constituent's surfaces that would alter the ion distribution [3].

Additionally, unless filtration is used, centrifugation may require up to $5 \mathrm{~min}$ separating the solid from the liquid phase. 
Many reactions on soil constituents are complete by the time or less [4-5]. For example, many ion exchange reactions on organic matter and clay minerals are complete after a few minutes, or even seconds [6-7]. Moreover, some reactions involving metal adsorption on oxides are too rapid to be observed with any batch or, for that matter, flow technique. For these reactions, one must employ one of the rapid kinetic techniques.

The use of flow method technique to describe adsorptiondesorption phenomena for clay minerals, soils and manufactured slow release fertilizers has many advantages over traditional batch technique or anion exchange resin. These include (i) Use of narrow soil to solution ratios with adsorbed concentrations that near to field conditions. (ii) Measurements at small time step the rate of reaction is possible (iii) the concentration of the adsorbed does not change as the reaction proceeds.

The soluble and exchangeable forms are regarded as rapidly available forms of $\mathrm{K}$ : they are replenished by nonexchangeable K (NEK) when they are depleted as a result of plant removal and/ or leaching [8-9] and perhaps by large increases in microbial activity [10]. In this point [11-32] reported that the amounts of maximum NEK accounted for $21-56 \%$ of the total $\mathrm{K}$ of the soils tested. NEK in soil is bound coulomb-bialy to negatively charged clay interlayer surface sites and this binding force exceeds the hydration forces between individual $\mathrm{K}^{+}$ions [13-14].

The stirred flow chamber technique as developed by [1516] is an improvement over the continuous flow method, involves the introduction of an adsorbed solution of known concentration onto a thin wet lay of soil. Despite the advantages of the stirred flow method over the continuous flow and most batch techniques in measuring rate of soil chemical process, one of the biggest shortcomings of this method is the clogging of the filter.

Electrical stirred Flow Unit (ESFU) was manufactured in NRC by [17-18] to try to elevate the most common problems found in such techniques. The estimation of $\mathrm{K}^{+}$available to crops as well as most of the $\mathrm{K}^{+}$fertilizer recommendations are based on soil analyses and do not consider $\mathrm{K}^{+}$release from non- exchangeable fractions [19-20]. The common methods of estimation of $\mathrm{K}^{+}$available to crops as well as most of the $\mathrm{K}^{+}$fertilizer recommendations are based on soil analyses which mean a waste of time and a lot of efforts (Parker et al., 1989). The main aim of this study is to evaluate of short period the modified set up (ESFU) to apply generally in different kinetic studies and specifically in studying the kinetics of potassium adsorption from new Egyptian reclaimed soil treated with both compost and chemical fertilizers.

\section{Material and Methods}

\subsection{Soil Used}

El-Nubaria site represents new reclaimed area in Egypt and adjacent to a lot of farms cultivated with different crops.
The cultivated area of National Research Centre Farm previously cultivated with different crops before our experimental started and used drip irrigation system as a main type of irrigation. Some physical and chemical characterization of used soil were done according to the methods described by [21] and presented in table (1).

\subsection{Compost Preparation}

The residues of banana were composted for three months as follows:

1) Shredding or grinding the material prior to adding it to the pile. This will expose a greater surface area to the bacteria and fungi and greatly speed the process.

2) Mixing organic wastes of banana with rabbit manure at a rate of 3:1 to obtain a compost rich in nutrients content and narrow in $\mathrm{C} / \mathrm{N}$ ratio.

3) Mixing the pile with Effective microorganisms (EM).

4) Each layer of the pile was slightly moistened to reach about $60 \%$ of its water holding capacity.

5) Top, bottom and sides of the heap were well covered with plastic sheet, and left to decay.

6) The pile was turned every week from the top and sides into the center to enhance the aeration.

7) The compost is characterized by low moisture content, black to dark brown color, earthy odor consistent and stable nutrient concentrations, (Table 2).

Effective microorganisms (EM) were a mixed culture of beneficial microorganisms including a predominant population of (Bacillus subtilis F.50 and F.30), (B. Theremogensid F.64), (Trichodermareesei F.418) and yeast (Sacchromycescerevisiae F N.10). EM was brought from the Biotechnology Unit, Microbial Chemistry Dept. N.R.C.

Table 1. Some physical and chemical properties of the studied soils.

\begin{tabular}{ll}
\hline Characteristics & Value \\
\hline $\mathrm{pH}(1: 2.5$ soil : water ratio) & 8.11 \\
EC (Soil paste extraction) dSm ${ }^{-1}$ & 1.32 \\
Soluble cations (m.e./100g soil): & \\
Calcium & 0.48 \\
Magnesium & 0.12 \\
Potassium & 0.69 \\
Sodium & 0.06 \\
Soluble anions (m.e./100g soil): & \\
Bicarbonate & 0.22 \\
Chloride & 0.77 \\
Sulphate & 0.36 \\
Available nutrients (ppm): & \\
Phosphorus & 7.9 \\
Potassium & 186.63 \\
Organic matter & 0.47 \\
Calcium carbonate & 24.9 \\
Physical properties (\%): & \\
Sand & 68.91 \\
Silt & 16.57 \\
Clay & 14.52 \\
Textural class & Sandy loam \\
\hline
\end{tabular}


Table 2. Some physical and chemical properties of the compost in two seasons.

\begin{tabular}{|c|c|c|c|c|c|c|c|c|c|}
\hline \multirow{2}{*}{ Season } & \multicolumn{3}{|c|}{ Total nutrients } & \multirow{2}{*}{ OM\% } & \multirow{2}{*}{$\mathrm{C} / \mathrm{N}$ ratio } & \multirow{2}{*}{ EC dS/m 1:5 } & \multirow{2}{*}{ pH 1:2.5 } & \multirow{2}{*}{ OM\% } & \multirow{2}{*}{ WHC } \\
\hline & N\% & $\mathbf{P \%}$ & $\mathrm{K} \%$ & & & & & & \\
\hline First season & 1.23 & 0.79 & 2.042 & 25.21 & 11.9 & 5.63 & 7.47 & 25.21 & 110 \\
\hline Second season & 1.1 & 0.82 & 2.201 & 37.69 & 17.8 & 5.5 & 7.44 & 37.69 & 160 \\
\hline
\end{tabular}

\subsection{Experimental Technique}

In two summer seasons, field experiments were conducted in El-Nubaria site to study the relationship between type of fertilizer applied and the kinetic rate of $\mathrm{K}$ desorption from the soil. Three techniques of fertilization were applied to Corn cultivar Single cross 129 (white) (Zea mays) was obtained from Ministry of Agriculture, Giza, Egypt, these techniques are represented by: T1: $100 \%$ compost prepared by the authors, the rate of application based on their commended rate of total nitrogen for Corn crop

T2: $75 \%$ compost $+25 \%$ chemical fertilization

T3: $50 \%$ compost $+50 \%$ chemical fertilization

T4: $100 \%$ recommended chemical fertilization for corn applied based of the recommendation rate of the crop (120 kg $\mathrm{N} /$ fed. as ammonium sulfate $+30 \mathrm{~kg} \mathrm{P}_{2} \mathrm{O}_{5} / \mathrm{fed}$. as super phosphate $+24 \mathrm{~kg} \mathrm{~K} 2 \mathrm{O} /$ fed. as potassium sulfate)

$\mathrm{C}$ : Control release of $\mathrm{K}$ based on the native $\mathrm{K}$ fertilizer applied in previous crops grown in the same used soil.

Organic material, phosphorous and potassium fertilizers were added before sowing. Nitrogen fertilizer was added in three equal portions before cultivation, after two weeks from cultivation and after three weeks from second addition, respectively. All amendments were manually spread. Agricultural practices were followed according to the recommendations of Ministry of Agriculture in Egypt.

\subsection{Kinetic Models}

The linear form of several kinetic models i.e. First-Order, parabolic Diffusion, Elovich and power function (modified Freundlich) as shown in table (3) were compared in their ability to fit of $\mathrm{K}$ desorption from compo-fertilized treated soil samples using nonlinear regression procedure [22]. The higher coefficient of determination $\mathrm{R}^{2}$ and the lower standard error SE, the best-fitted equation(s) described the kinetics of $\mathrm{K}$ desorption in different treatments.

\subsection{Irrigation Requirement IR}

Since the water requirement IR applied to corn is an important factor in $\mathrm{K}$ bioavailability in soil system, in this work we evaluated two irrigation moisture regimes represent $80 \%$ and $60 \%$ of total water requirement on $\mathrm{K}$ desorbed from the used soil and subsequently the $\mathrm{K}$ bioavailability by corn. The data of water requirement was calculated by average 8 years of meteorological parameters using CROPWAT computer model [23] (according to the climatic data recorded at El-Bustan Weather Station), based on calculation using Penman Monteith equation and the Kc values presented in the program and also illustrated in [24].
Crops evaporate transpiration (ETc) was calculated according to the following formula:

$$
\mathrm{ETc}=\mathrm{Kc}^{*} \mathrm{ET}_{0}
$$

Where: ETc, crop evaporate transpiration in $\mathrm{mm} /$ day (ranged between 2.19-6.19 $\mathrm{mm} /$ day in growing seasons); $\mathrm{ET}_{0}$, reference evaporate transpiration in $\mathrm{mm} /$ day (ranged between $5.4-7 \mathrm{~mm} /$ day in the growing seasons); $\mathrm{Kc}=$ crop coefficient.

Table 3. Kinetic models Applying to describe Potassium adsorption in the studies soils.

\begin{tabular}{lll}
\hline Model & Equation & References \\
\hline Power Function & $\mathrm{Y}=\mathrm{k}_{\mathrm{d}} \mathrm{t}^{\mathrm{b} \downarrow}$ & {$[15]$} \\
Elovich & $\mathrm{Y}=\ln \alpha+\beta \ln \mathrm{t}$ & {$[24]$} \\
First-order & $\mathrm{Log} \mathrm{Y}=\log \mathrm{q}_{0}-\mathrm{k}_{1} \mathrm{t}$ & {$[24]$} \\
Parabolic Diffusion & $\mathrm{Y}=\mathrm{b}+\mathrm{R} \mathrm{t}^{1 / 2}$ & {$[15]$} \\
\hline
\end{tabular}

$\mathrm{Y}=$ the amount of potassium adsorbed in time $\mathrm{t}$

$\mathrm{k}_{\mathrm{d}}=$ desorption rate coefficient in $\mathrm{mg} \mathrm{kg}^{-1}$ soil $\mathrm{min}^{-1}$

$\mathrm{b}^{\backslash}=$ intensity constant in $\mathrm{mg} \mathrm{K} \mathrm{kg}{ }^{-1}$ soil

$\alpha=$ a constant related to the initial rate of $\mathrm{K}$ adsorbed in $\mathrm{mg} \mathrm{K} \mathrm{kg}{ }^{-1} \mathrm{~min}^{-1}$

$\beta=$ a constant in $\mathrm{mg} \mathrm{kg}^{-1}$ soil

$\mathrm{b}=$ intensity constant in $\mathrm{mg} \mathrm{K} \mathrm{kg}{ }^{-1}$ soil

$\mathrm{R}=$ the apparent diffusion rate coefficient in $\mathrm{mg} \mathrm{K} \mathrm{kg}^{-1}$ soil $\mathrm{min}^{-1}$

$\mathrm{q}_{0}=$ the maximum amount of $\mathrm{K}$ adsorbed $\mathrm{mg} \mathrm{K} \mathrm{kg}^{-1}$ soil

$\mathrm{k}_{1}=$ the rate constant of the reaction in $\mathrm{sec}^{-1}$

\section{Results and Discussion}

\subsection{Kinetic of K Desorbed from the Studied Soil as Affected by Type of Fertilizer Applied}

Although data not shown, the authors didn't find any significance between the application of 100 and $80 \%$ of IR in $\mathrm{K}$ uptake by corn, consequently, the discussion will be only focused on 80 and $60 \%$ of IR. Figure (1) represents the kinetics of potassium release from the treated soils and irrigated with $80 \%$ of IR after 14 days of reaction time. Because of the $\mathrm{S}$ shape observed for $\mathrm{K}$ desorption data in different treatments through the entire reaction time, the data will be divided into two stages, the first stage was the rate of $\mathrm{K}$ released through 1-60 min and the second one was the data obtained through the rest of reaction time i.e. 120-10080 min.

Dividing the entire reaction time into two stages, led to have almost straight lines in both short reaction time (A) and long one (B) in all treatments tested. Data shows the $\mathrm{K}$ release from compost individually gave the lowest values compared with other treatments tested. By mixing compost prepared with the chemical fertilizers, $\mathrm{K}$ released was significantly increased compared to both control and the compost applied individually. Data also showed that the maximum $\mathrm{K}$ desorbed from the soil was $221 \mathrm{ppm}$ in the case 
of compost; gradually increase up to 257 and $277 \mathrm{ppm}$ in $\mathrm{T} 2$ and $\mathrm{T} 3$ respectively. The highest value however, was observed in chemically fertilized soil $303 \mathrm{ppm}$.

Although data not shown, decreasing the irrigation requirement to $60 \%$ directly decreased the rate of $\mathrm{K}$ desorption in all treatments including control. For example, decreasing the IR led to decrease the maximum release of $\mathrm{K}$ in T4 to about $255 \mathrm{ppm}$ which almost represents $15 \%$ less than the high IR applied. In the organic treated soil T4, the decreasing order observed was less than the chemical treated one by about $10 \%$ numerically equal to about $200 \mathrm{ppm}$, worth to mention that the other treatments were decreased with varied percentage of decrease

Dividing the entire reaction time into two stages S1 and S2 led to have straight line in both stages of all treatments which represents that more than one mechanism controlled the release of $\mathrm{K}$ from the treated soils. In addition, it should be mention that all treatment kept their order in $\mathrm{K}$ release in both stages. It is generally believed that there is no single equation that described equally well the kinetic data of all soils [25].

\subsection{Kinetic Parameters of K Desorption from the Fertilized Used Soil as Affected by Irrigation Cycle and Type of Fertilizer Applied}

Prior the narrative in kinetic work, it should be mention that the succession of more than one model describing the rate of $\mathrm{K}$ desorption from the different treatments applied meaning more than one mechanisms controlled $\mathrm{K}$ uptake by corn plant tested in this work. Also, selection of the best fitted model(s) was based on the higher coefficient of determination and the lower standard error the best fitted model(s). Accordingly, although the all models well described the kinetic data we found that MFE was the best in describing the rate of $\mathrm{K}$ desorption ( $\mathrm{R} 2$ ranged between $0.98 * *-0.99 * *)$ since it gave the lower SE, followed by Elovich $(0.96 * *-0.99 * *)$ and for less extent $1^{\text {st }}$ order and parabolic diffusion models (R2 ranged between $0.89 * *$ $0.92 * *)$.

The power function (modified Freundlich) equation in the linear form is: $\ln _{t}=\operatorname{lnk}_{d}+b \ln t$. The integrated form is $q_{t}=$ $\mathrm{k}_{\mathrm{d}} \mathrm{t}^{\mathrm{b}}$

here $\mathrm{q}_{\mathrm{t}}$ the amount of $\mathrm{K}$ release at time $\mathrm{t}, \mathrm{k}_{\mathrm{d}}$ and $\mathrm{b}^{\prime}$ are constants. Taking the derivation of integrated form:

$$
\mathrm{dq} / \mathrm{dt}=\mathrm{k}_{\mathrm{d}} \mathrm{b}^{\backslash} \mathrm{t}^{\mathrm{b} \backslash-1}
$$

Where $k_{d}$ is directly proportional to the rate of $\mathrm{K}$ release and was considered as the apparent desorption rate coefficient. The effect of $b^{\prime}$ on potassium release is more complex. The reaction rate is proportional to $\mathrm{k}_{\mathrm{d}}$ only at $\mathrm{t}=1$ in which case:

$$
\mathrm{dq} / \mathrm{dt}=\mathrm{k}_{\mathrm{d}} \mathrm{b}^{\prime}
$$

The $b^{\prime}$ value is convenient to use as an estimate of the initial release rate when comparisons are made between power function equations. It is, however, designated as the reversibly adsorbed potassium.

The kinetic parameters which describe the kinetic parameters of $\mathrm{K}$ release from soil irrigated with 80 and $60 \%$ of IR are presented in tables 3 and 4 . The rate constants namely; $\mathrm{K}_{\mathrm{d}}$ of modified Freundlich, $\mathrm{R}$ of the parabolic Diffusion, $\mathrm{k}_{1}$ of the first-order and $\beta$ of Elovich equations, all were considerably increased in the $100 \%$ chemical fertilization applied T4 than in both purely organic fertilization and the mixture of chemical and organic types. The average values of MFE as an example in chemical fertilized soils were 0.26 decreased to 0.22 in organic fertilized soil and take in between values for the mixture of both organic and inorganic fertilizers. In contrast, data showed that the capacity factor b of MFE took a reverse trend reached to 1.55 for organic fertilizer and decreased to 1.41 in chemically fertilized soil.

Decreasing the IR to $60 \%$ applied to corn decreased the $K_{d}$ values for both chemical and organic fertilized soil to be 0.24 and 0.21 in chemical and organic fertilized soils respectively. Also, it was noted that although the capacity factor gave a reverse trend, the obtained values was less than the $80 \%$ IR.

The $\beta$ value, the slop of the kinetic data plotted according to Elovich equation (in of time against $\mathrm{P}$ concentration) was shown by [26] to be inversely proportional to the soil supplying power of ion to plant.

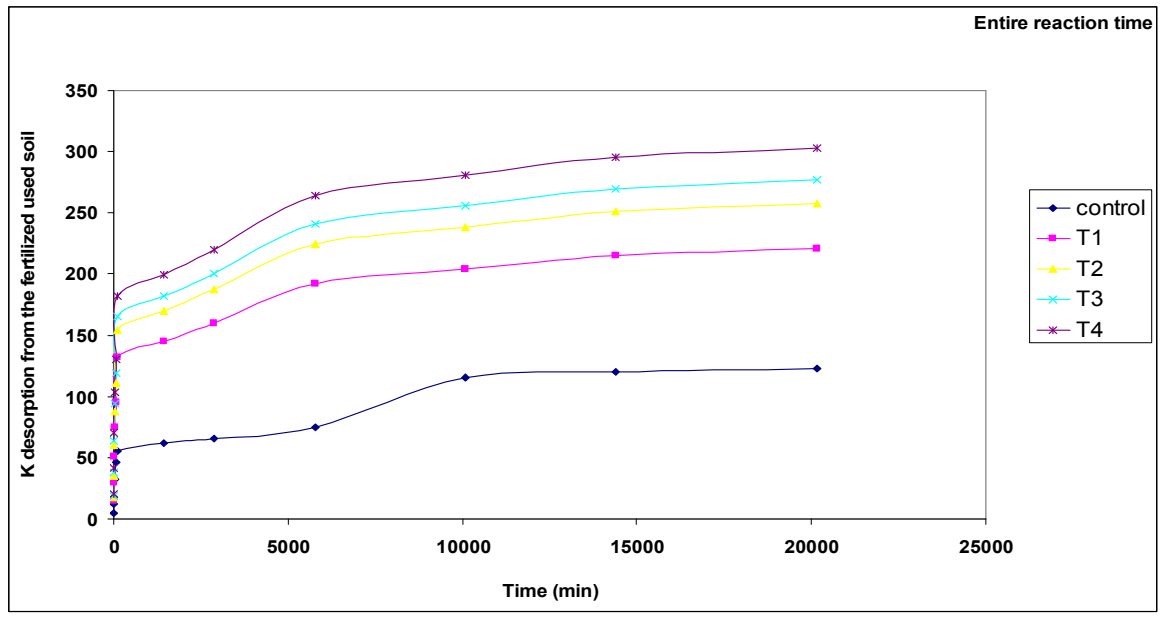



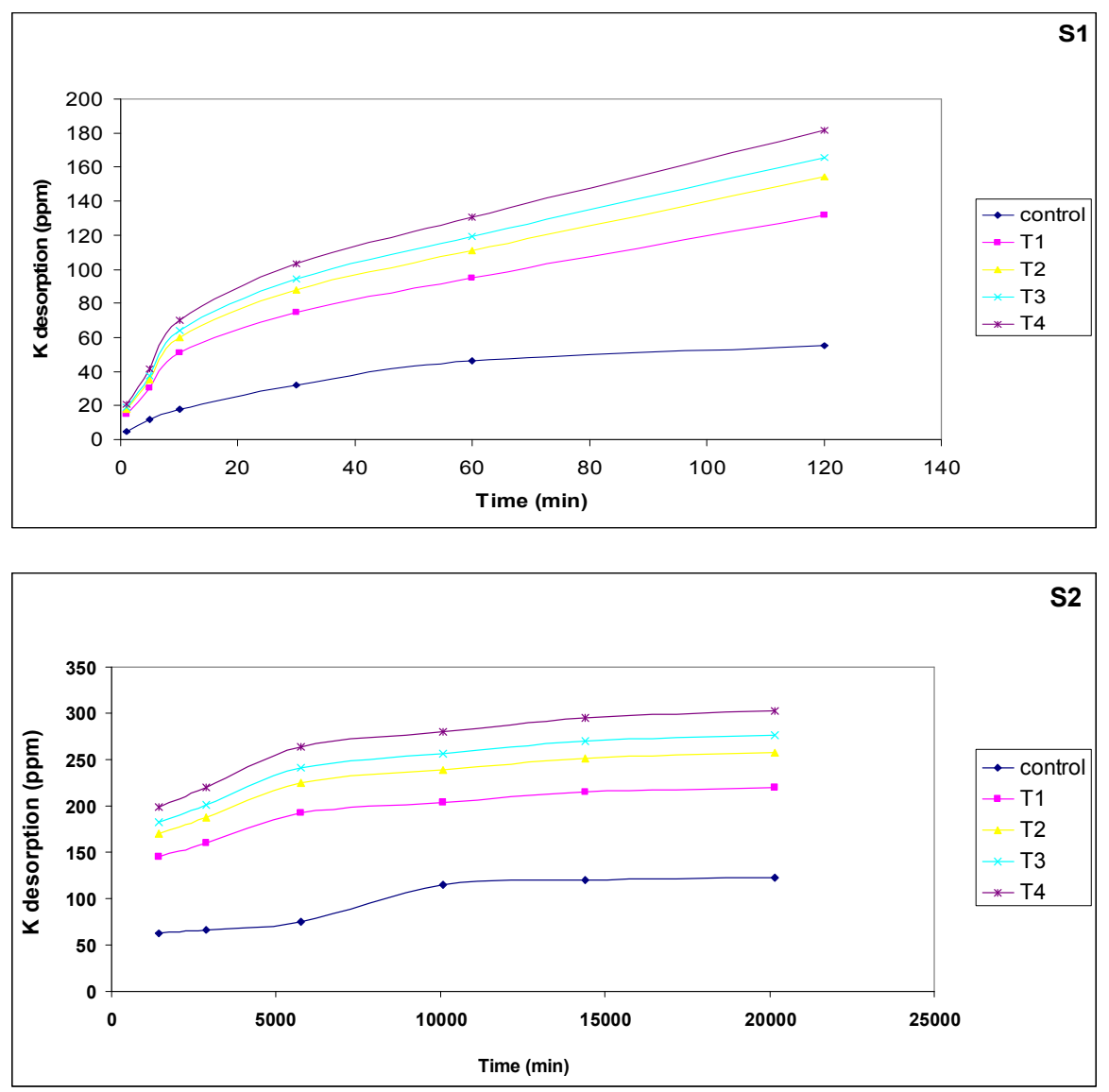

Figure 1. Kinetic of $K$ desorbed from the treated soils in both entire reaction time and different stages.

Chien and Clayton [27] showed that the decrease in $1 / \beta$ and or increase in $\alpha$ enhance the reaction rate. Sikora et al. [28] reported that $\beta$ constant is an important parameter to define desorption rate $\mathrm{dI} / \mathrm{dt}$ throughout the whole dissolution period of added ion. Moreover, a low $\beta$ value is associated with higher dissolution rate and a greater buffering of iondissolution rate with the increase in ion concentration, compared with high $\beta$.

The $\beta$ value in Elovich equation shown to be inversely related to the $\mathrm{K}$ supplying power of the soil was 8.25 and 8.8 in $\mathrm{T} 2$ and $\mathrm{T} 3$ respectively represented the preferring of applying 50:50 chemical to organic fertilizers instead of increasing organic fertilizer over the chemical one. These results clearly demonstrate the higher potential of $\mathrm{K}$ release in the soils treated with chemical ones. The constants that describe the capacity of $\mathrm{K}$ in used models i.e. $\mathrm{b}^{\prime}$ in modified Freundlich, $\mathrm{b}$ in parabolic diffusion, $\mathrm{q}_{0}$ in the first-order models, all were higher in the fertilized soil compared to control. Therefore, Potassium uptake from the treated soils was considerably higher than from the untreated one. In addition, all kinetic parameters values decreased by decreasing IR applied.

Diffusion kinetic model was also succeeded in describing the rate of $\mathrm{K}$ desorbed from the treated soil. According to data presented in tables 3 and 4 , decreasing the IR from $80 \%$ to $60 \%$, led to decrease the rate of $\mathrm{K}$ from 1.79 to 1.69 in $\mathrm{T} 4$ (chemically fertilized soil), in other words, the diffusion mechanism of $\mathrm{K}$ to plant used was influenced by the IR and assumed to be influenced the concentration of $\mathrm{K}$ in plant. The capacity factor represented by $\mathrm{b}$ decreased from 1.41 to 1.35 . It is well known that the role of $\mathrm{K}$ in the plant could be summarized in photosynthesis and plant food formation, sugar and carbohydrate production, transport, and storage, however, the important function related with cell Turgot and through this the opening and closing of leaf stoma. This in turn controls the plants ability to effectively respond to drought stress. Also, $\mathrm{K}$ is transported within the soil and is absorbed by plant roots in the soil water. Therefore a water deficiency results in less $\mathrm{K}$ absorption.

\subsection{Correlation Analysis Between $K$ Desorption from the Fertilized Soils and the Uptake of K by Corn}

The $\mathrm{K}$ uptake by corn grown in treated soils of the new reclaimed area was correlated with the constants of the four tested kinetic models (table 5). The correlation coefficient was highly significant with the kinetic parameters representing the rate of $\mathrm{K}$ release in the order: The modified Freundlich rate coefficient $\left(\mathrm{K}_{\mathrm{d}}\right)\left(\mathrm{r}=0.98^{* *}\right)>$ the rate constant $(\beta)$ in the Elovich equation $\left(\mathrm{r}=0.97^{* * *}\right)>$ the rate of $\mathrm{K}$ release coefficient $(\mathrm{R})$ in the parabolic diffusion $(\mathrm{r}=$ $\left.0.96^{* *}\right)>$ the initial rate of K-release $\left(\mathrm{q}_{0}\right)$ in $1^{\text {st }}$ order equation $\left(\mathrm{r}=0.85^{* *}\right)$. The $\beta$ coefficient in Elovich which was found to be inversely correlated with the $\mathrm{K}$ supplying power of the soil 
[25-29], and inversely related to the rate of $\mathrm{K}$ release from soil [26-30] was inversely correlated with the plant $\mathrm{K}$ uptake $\left(\mathrm{r}=0.97^{* *}\right)$. It should be recalled that both Elovich and modified Freundlich equations offered the best fit to the $\mathrm{K}$ release data from the tested adequate fit to the description data, its rate of diffusion coefficient (R) gave the high correlation coefficient with the cumulative K uptake and with the uptake of K. Similarly the first-order equation offered a lower fit to the $\mathrm{K}$ release data but the rate constant $\mathrm{k}_{0}$ of the equation was highly correlated with plant $\mathrm{K}$ uptake.

The correlation coefficients in the same table show that $\mathrm{K}$ bioavailability may be less dependent on the capacity than the rate parameters due to lower correlation coefficients and the less significant correlation between the plant $\mathrm{K}$ uptake and the intensity parameters in the tested equations[31]. The $b^{\backslash}$ value in modified Freundlich equation denotes the $\mathrm{K}$ capacity and was not significantly correlated with plant $\mathrm{K}$ uptake. The $\mathrm{b}$ value, which is the concentration of $\mathrm{K}$ at the time of ESFU work in the diffusion equation, showed significant correlation with plant $\mathrm{K}$ uptake but the correlation coefficient $(\mathrm{r}=0.63 * * *)$ was considerably less than with the rate of $\mathrm{K}$ release $\left(\mathrm{r}=0.95^{* * *}\right)$. The $\mathrm{q}_{0}$ value in the first-order kinetic equation which represent the $\mathrm{K}$ intensity was less significantly correlated with K-uptake $(\mathrm{r}=0.57 * *)$ than the rate kinetic $\mathrm{R}\left(\mathrm{r}=0.83^{* * *}\right)$.

The correlation coefficients in the same table show that $\mathrm{K}$ bioavailability may be less dependent on the capacity than the rate parameters due to lower correlation coefficients and the less significant correlation between the plant $\mathrm{K}$ uptake and the intensity parameters in the tested equations. The $\mathrm{b}$ value in modified Freundlich equation denotes the $\mathrm{K}$ capacity and was not significantly correlated with plant $\mathrm{K}$ uptake. The $\mathrm{b}$ value, which is the concentration of $\mathrm{K}$ at the time of ESFU work in the diffusion equation, showed significant correlation with plant $\mathrm{K}$ uptake but the correlation coefficient( $\mathrm{r}$ $\left.=0.63^{* * *}\right)$ was considerably less than with the rate of $\mathrm{K}$ release $\left(\mathrm{r}=0.95^{* * *}\right)$. The $\mathrm{q}_{0}$ value in the first-order kinetic equation which represent the $\mathrm{K}$ intensity was less significantly correlated with K-uptake $(\mathrm{r}=0.57 * *)$ than the rate kinetic $\mathrm{R}\left(\mathrm{r}=0.83^{* * *}\right)$.

The high and significant correlation between $\mathrm{K}$ uptake and the kinetic parameters of the best models table (4), namely $\mathrm{k}_{\mathrm{d}}, \mathrm{R}, \beta$, and $\mathrm{k}$, however, gave higher correlation's with the plant

$\mathrm{K}$ uptake indicating that these parameters, especially the diffusion rate coefficient (R) can better estimate $\mathrm{K}$ bioavailability than the other methods in describing $\mathrm{K}$ uptake by plant. With an exception observed in the $1^{\text {st }}$ order, Potassium uptake by corn in the $2^{\text {nd }}$ season highly significant $r$ values were observed with the capacity factor more than the rate parameters of tested models. For example, in the MFE, the $r$ value of $b \backslash$ was $0.91^{* *}$ meanwhile the $\mathrm{Kd}$ was $0.72^{\text {ns }}$, this result may represents the variation of $\mathrm{K}$ mechanism with repeating of crop cultivated in the same soil. It should mention that the same trend was observed in diffusion and Elovich models.

The parameter in Elovich equation that may stand for the initial rate of $\mathrm{K}$ release had no significant relation with plant $\mathrm{K}$ uptake, (Table5). As with the $1^{\text {st }}$ season, both the $\mathrm{b}$ value in the diffusion equation and the $\mathrm{q}_{0}$ in the first-order equation, which represent $\mathrm{K}$ capacity, showed high significant correlation with plant $\mathrm{K}$ uptake $\left(\mathrm{r}=0.94^{* *}\right.$ and $\left.0.97^{* *}\right)$.

Almost all kinetic parameters describing the rate of $\mathrm{K}$ release in different treatments of the studied soil were highly correlated with plant $\mathrm{K}$ uptake and may be used as indices for $\mathrm{K}$ bioavailability if the rate of release proved to be a determining step for K-uptake by plant. In the $2 \mathrm{~ns}$ season, however, only the $1^{\text {st }}$ order rate coefficient $\left(\mathrm{k}_{1}\right)$ was highly correlated with plant K-uptake.

This parameter assumed superiority over other capacity parameters possible indices for $\mathrm{K}$ bioavailability in the $1^{\text {st }}$ season. These results agree with those of [25], [26], [28], their results on phosphate showed that both constants were related to the $\mathrm{P}$ supplying power of soil and or the rate of $\mathrm{P}$ release from soil had significant relationship between $\beta$ and $P$ bioavailability to sorghum did not establish that $\mathrm{P}$ dissolution is a rate determining step to P-uptake since similar relationship existed between $\beta$ and equilibrium ion.

On the other hand, [26-32] argued that the potential rate of $\mathrm{P}$ release from the soil as a whole was at least 250 times as great as the rate of P-uptake by crop.

Table 4. Kinetic parameters of selected equation describe K desorption from compo-fertilized soil under application of $60 \%$ of IR.

\begin{tabular}{|c|c|c|c|c|c|c|c|c|}
\hline \multirow{2}{*}{ Treat } & \multicolumn{2}{|c|}{ MFE. } & \multicolumn{2}{|c|}{ Parabolic diffusion equation } & \multicolumn{2}{|c|}{ Elovich equation } & \multicolumn{2}{|c|}{$1^{\text {st. }}$ order equation } \\
\hline & $\mathbf{k}_{\mathrm{d}}$ & $\mathbf{b}^{\prime}$ & $\mathbf{R}$ & $\mathbf{b}$ & $\beta$ & $\alpha$ & K1 & $q_{0}$ \\
\hline Crl. & 0.17 & 0.93 & 0.73 & 21.56 & -3.43 & 10.40 & -0.86 & 1.43 \\
\hline $\mathrm{T} 1$ & 0.21 & 1.52 & 1.19 & 88.25 & 6.37 & 26.36 & -0.82 & 3.12 \\
\hline $\mathrm{T} 2$ & 0.22 & 1.48 & 1.44 & 80.16 & 7.51 & 24.08 & -0.71 & 2.92 \\
\hline $\mathrm{T} 3$ & 0.23 & 1.42 & 1.52 & 74.38 & 8.01 & 22.43 & -0.63 & 2.85 \\
\hline $\mathrm{T} 4$ & 0.24 & 1.35 & 1.69 & 63.23 & 8.82 & 19.18 & -0.50 & 2.79 \\
\hline
\end{tabular}

Table 5. Correlation coefficient (r) for the relationship between K uptake by Corn plants grown in treated soil and kinetic parameters of selected equations.

\begin{tabular}{|c|c|c|c|c|c|c|c|c|}
\hline \multirow{2}{*}{ Treat } & \multicolumn{2}{|c|}{ MFE } & \multicolumn{2}{|c|}{ Parabolic diffusion equation } & \multicolumn{2}{|c|}{ Elovich equation } & \multicolumn{2}{|c|}{$1^{\text {st. }}$ order equation } \\
\hline & $\mathbf{k}_{\mathbf{d}}$ & $\mathbf{b}^{\prime}$ & $\mathbf{R}$ & b & $\beta$ & $\alpha$ & K1 & $\mathbf{q}_{0}$ \\
\hline Crl. & 0.19 & 0.96 & 0.77 & 24.76 & -4.76 & 11.43 & -0.65 & 4.3 \\
\hline $\mathrm{T} 1$ & 0.22 & 1.55 & 1.30 & 92.34 & 7.00 & 28.97 & -0.63 & 3.43 \\
\hline $\mathrm{T} 2$ & 0.23 & 1.51 & 1.52 & 84.25 & 8.25 & 26.46 & -0.58 & 3.40 \\
\hline T3 & 0.24 & 1.48 & 1.63 & 78.58 & 8.80 & 24.65 & -0.53 & 3.35 \\
\hline $\mathrm{T} 4$ & 0.26 & 1.41 & 1.79 & 67.13 & 9.69 & 21.08 & -0.50 & 3.23 \\
\hline
\end{tabular}




\section{Conclusion}

In this study, our results indicate that these rate parameters could be used as indices for K bioavailability since they show superiority over other P intensity parameters. Extracted $\mathrm{K}$ by the ESFU for 14 days, however, offers a simple and equally accurate measure for $\mathrm{P}$ bioavailability. In addition, the important of this study may emphasized that the $80 \%$ of IR was the best irrigation treatment in having optimum condition of $\mathrm{K}$ to growing plants since it makes stimulation of plants to increased $\mathrm{K}$ uptake. The decreasing of IR to $60 \%$ decreased the ability of the tested crop to absorb K and may deficiency symptoms will be established by decreasing the water requirements.

\section{References}

[1] Sparks, D. L. (1985). Kinetics of ionic reactions in clay minerals and soils. Advances in Agronomy. 38: 231-265.

[2] Amer, F., Bouldin, D. R., and Black, C. A. (1955). Characterization of soil phosphorus by anion exchange resin adsorption and $\mathrm{P}^{32}$ equilibration. Plant and soil 6: 391-394

[3] Sparks, D. L. (1989). Kinetics of soil chemical processes. Academic Press, San Diego, CA

[4] Harter R. D. and Lehmann, R. G. (1983) Use of kinetics for the study of exchange reactions in soils. Soil Sci. Soc. Am. J.

[5] Jardine, P. M., and Sparks, D. L. (1984). Potassium - Calcium exchange in the multi-reactive soil system. I. Kinetics. Soil Sci. Soc. Am. J. 48:39- 45.1208.

[6] Sparks, D. L. and Huang P. M. (1985). Physical chemistry of soil potassium. Munson, R. D. (ed.) Potassium in Agriculture. Am. SOC. Agronomy, Madison. pp. 201-276.

[7] Sparks, D. L. (1986). Kinetics of reactions in pure and in mixed systems. In "Soil physical chemistry" (D. L. Sparks, ed.), pp 83 - 178 CRC press, Boca Raton, Florida

[8] Sparks, D. L. (1988). Kinetics of Soil Chemical Processes. Academic Press, San Diego. pp. 4-38.

[9] Römheld, V. and Kirkby, E. A. (2010). Research on potassium in agriculture: needs and prospects. Plant Soil 335, 155-180

[10] Zörb, C., Senbayram, M. and Peiter, E. (2014). Potassium in agriculture - status and perspectives. J. Plant Physiol. 171, 656-669

[11] Prakash, V., Kundu, S., Ghosh, B. N., Singh, R. D. and Gupta, H. S. (2002). Yield response of soybean (Glycine max) and wheat (Triticumaestivum) to potassium and changes of potassium status in soil after long-term sequential cropping. Indian J. Agri. Sci. 72, 514-518

[12] Kulcheski, F. R., Côrrea, R., Gomes, I. A., de Lima, J. C. and Margis R. (2015). NPK macronutrients and micro RNA homeostasis. Front. Plant Sci. 6, 451

[13] Wang, H. Y., Cheng, W., Li, T., Zhou, J. M. and Chen, X. Q. (2016). Can non-exchangeable potassium be differentiated from structural potassium in soils? Pedo-sphere 26, 206-215
[14] Zörb, C., Senbayram, M. and Peiter, E. (2014). Potassium in agriculture - status and perspectives. J. Plant Physiol. 171, 656-669

[15] Moritsuka, N., Yanai, J. and Kosaki, T. (2004). Possible processes releasing non-exchangeable potassium from the rhizosphere of maize. Plant Soil 258, 261-268

[16] Sparks, D. L.; Zelazny, L. W., and Matens, D. C. (1980a). Kinetics of potassium exchange in paleudult from the coastal plain of Virginia. Soil Sci. Soc. Am. J., 44:37 - 40.

[17] Zaghloul, A. M. (2002) Kinetics of potassium adsorption in some soils of Egypt using Electrical Stirred Flow unit (ESFU). Egyptian J. of soil Sci., 42, 463 - 471.

[18] Wahba, M. M.; Sherine, M. Shehata and Zaghloul, A. M. (2012). Treatment of polluted water by clay minerals to eliminate the heavy metals. International journal of research in management. 2(3) 16:24

[19] Parker, D. R., D. L. Sparks, G. J. Hendricks, and M. C. Sadusky. (1989). Potassium in Atlantic Coastal Plain Soils. I. Soil characterization and distribution of potassium. Soil Sci. Soc. Am. J. 53:392-396.

[20] Sikora, F. J., Copeland, J. P.; Mullins, G. L., and Bartos, J. M. (1991). Phosphorus dissolution kinetics and bioavailability of water-insoluble fractions from mono-ammonium phosphate fertilizers. Soil Sci. Soc. Am. J., 55:362-36

[21] Cottenie, A.; Verlea, M.; Krekens, L.; Velghe, G., and Bcamerlynck, R. (1982). Chemical analysis of plant and soils Lab. Anal. Agroch. Fac. Agric. State University Gent., Belgium.

[22] SAS Institute, (1985) SAS user's guide, Statistics, Version 5 ed. SAS Ins., Cary, NC.

[23] FAO. (1992). Agro-Meteorological Data Systems, FAO, Rome

[24] Allen, R. G, Pereira, L. S., Raes, D. and Smith, m., (1998). Crop evaporate transpiration - Guidelines for computing crop water requirements - FAO Irrigation and drainage paper 56, FAO, Rome.

[25] Raven, K. P., and Hossner, L. R. (1994). Soil phosphorus desorption kinetics and its relationship with plant growth. Soil Sci. Soc. Am. J., 58: 416 - 423

[26] Cooke, G. W. (1970). The control of soil fertility. The English Language Book Society and Crosby Lockwood \& son LTD 26 old Brompton Boad. London. SW7

[27] Elkhatib, E. A., and Hern, J. L. (1993). Kinetics of phosphorus desorption from Appalachian soils. Soil Sci., 145: 222 - 229.

[28] Chien, S. H. and Clayton, W. R. (1979). Application of Elovich equation to the kinetics of phosphate release and sorption in soils. Soil Sci. Soc. Am. J. 44: 265-268

[29] Barbagelata, P. A. and Mallarino, A. P. (2013). Field correlation of potassium soil test methods based on dried and field-moist soil samples for corn and soybean. Soil Sci. Soc. Am. J. 77, 318-327

[30] Holland, J., Conyers, M., Orchard, B. and Poile, G. (2014). Soil potassium relationships, uptake efficiency and availability for six distinctive soils incentral and southern New South Wales, Australia. Soil Res. 52, 129-139 
[31] Hosseinpur, A. R. and Motaghian, H. R. (2013). Application of kinetic models in describing soil potassium release characteristics and their correlations with extracted by chemical methods. Pedo-sphere 23, 482-492
[32] Ting Li1, Huoyan Wang1, Zijun Zhou, Xiaoqin Chen and Jianmin Zhoul. (2016). A new grading system for plant available potassium using exhaustive cropping techniques combined with chemical analyses of soils. Scientific Reports 6, Article number: 37327 